\title{
Toxicity Study in a Pig Model of Intraperitoneal Collagenase as an "Enzymatic Scalpel" Directed to Breaks Stroma in Order to Generate a New Perspective for Peritoneal Carcinomatosis Approach. An Experimental Research.
}

\section{Mariano García-Arranz ( $\nabla$ mariano.garcia@quironsalud.es )} Health Researchy Institute Fundacion Jimenez Diaz https://orcid.org/0000-0001-8142-1373

\section{Pedro Villarejo-Campos}

Fundacion Jimenez Díaz University Hospital

Javier Barambio

Fundacion Jimenez Díaz University Hospital

\section{Soledad Garcia Gómez-Heras}

Universidad Rey Juan Carlos

\section{Luz Vega-Clemente}

health Research Institute Fundacion Jimenez Diaz

Héctor Guadalajara

Fundacion Jimenez Diaz University Hospital

\section{Damian Garcia-Olmo}

Fundacion Jimenez Diaz University Hospital

\section{Research Article}

Keywords: Toxicity, Histologically

Posted Date: October 25th, 2021

DOl: https://doi.org/10.21203/rs.3.rs-970756/v1

License: (c) (i) This work is licensed under a Creative Commons Attribution 4.0 International License. Read Full License

Version of Record: A version of this preprint was published at World Journal of Surgical Oncology on February 25th, 2022. See the published version at https://doi.org/10.1186/s12957-022-02524-2. 


\section{Abstract}

Background: The purpose of this study was to evaluate the toxicity using collagenase in peritoneal cavity as a preliminary step to generate a treatment that breaks the stroma surrounds the tumors.

Methods: 8 pigs were treated at 2 different collagenase concentrations, previously tested in rats by our groups, with time and temperature control using peritoneal lavage system (PRS System, Combat Medical Ltd) identical to use in human surgeries to treatments through HIPEC, plus 2 pigs were treated with peritoneal lavage only. Blood and peritoneal fluid samples were collected pre-treatment, post-treatment and at $24 \mathrm{~h}$ after treatment. Histological studies and blood collagenase levels were measured.

Results: No complications were observed during the surgeries. Images during treatments showed the release of peritoneal tissue during collagenase washes. After surgery the animals showed no signs of pain. Diet and mobility were normal at $4 \mathrm{~h}$. There were no significant differences in hematological and biochemical parameters. MMP1 and MMP2 were quantified in all samples and no differences were found in blood collagenase levels between pre-treatment, post-treatment and $24 \mathrm{~h}$ post-treatment.

None of collagenase treated animals showed peritoneal adhesions at the second surgery. Histologically, peritoneal organs and serous structures, did not show any microscopic alteration associated with collagenase treatment in any groups

Conclusion: Lavage of the peritoneal cavity with doses of up to $(100,000$ Collagen Digestion Unit/animal for 30 minutes is safe and removes connective tissue from the peritoneal cavity.

\section{Background}

Solid tumors are surrounded by a stroma resistant to most drugs that makes their nonsurgical approach difficult, this microenvironment protect to tumor against therapeutic agents to target cancer cells' [1].Breaking this extracellular matrix (composed mainly of collagen) could facilitate the penetration of drugs into tumors and improve the therapeutic tumor response[2-4].Previous work by our group on rats has shown that the use of intraperitoneal collagenase, controlling the time and concentration, degrades the tumor stroma without causing damage to the organs and tissues of the animals[5].In order to obtain authorization from regulatory agencies, we decided to conduct a toxicity study of the application of collagenase at the peritoneal level on a large animal model.

Degradation of the extracellular matrix using intravenous collagenase has been shown to increase drug penetration in murine tumors[6]. An approach using a system to apply collagenase in a tumor rat model has shown that control of time and concentration of enzymes is essential[7].

In our previous study we analyzed the effect of intraperitoneal collagenase on a rat model with peritoneal carcinomatosis. This study is the first in a large animal to demonstrate the non-toxicity of collagenase by controlling time and concentration as a step prior for using in clinical practice. We decided to use the 
Landrace-White Langer pig since the coagulation parameters in adult animals are similar to that of humans[8]. The study design was carried out in accordance with the recommendations of the Spanish Agency for Medicines and Health Products (AEMPS) as a prior step to authorizing a clinical trial in humans.

\section{Methods}

10 animals of both sexes and $25-30 \mathrm{Kg}$ were divided in 3 groups. Group 1, 6 animals underwent lavage of the peritoneal cavity at $50000 \mathrm{CDU}$ (Collagen digestion unit) or $369.2 \mathrm{~g}$ of collagenase (GIDZyme-2 GMP, Spain) in 1.5L of peritoneal dialysis solution; Group 2, 2 animals underwent lavage of the peritoneal cavity at $100000 \mathrm{CDU}$ or $738.4 \mathrm{~g}$ of collagenase in $1.5 \mathrm{~L}$ of peritoneal dialysis solution; and Group 3,2 animals underwent lavage of the peritoneal cavity with $1.5 \mathrm{~L}$ of peritoneal dialysis solution. In all treatment we used temperature control system and peritoneal lavage (PRS System, Combat MedicalLtd). The procedure was approved by the OEBA of the Jiménez Díaz Foundation Health Research Institute and Community of Madrid (No.PROEX93.1/20). The work has been reported in accordance with the ARRIVE guidelines (Animals in Research: Reporting In Vivo Experiments)(9).The number of animals was recommendation of OEBA to minimize the number of animals and generate pharmacological conclusions. All animals had an acclimatization period of $48 \mathrm{~h}$ prior to surgery.

No prior randomization was performed, trials were sequential, first a control group, a second group with a low dose of treatment and finally a group with the highest dose.

\section{Surgery}

After anesthesia, the animal was placed in a supine position, a laparoscopic approach was performed using a Hasson trocar. Four 12-mm trocars were inserted, upper right and left quadrants in both iliac fossae. Subsequently, pressurized peritoneal cavity using $\mathrm{CO}_{2}$ was performed, then the peritoneal cavity was tempered with washing solution oreheated for at least 10 minutes. The next step was a peritoneal cavity lavage for 30 minutes with collagenase (if applicable to the group) by means of the peritoneal lavage pump (Combat System). The filling volume of the abdominal cavity was individualized according to the capacity of each animal through the PRS system, usually $1.5 \mathrm{~L}$ of washing solution. A homogeneous intraperitoneal temperature of $37-38^{\circ} \mathrm{C}$ was maintained during all procedure. For intraoperative monitoring of hemodynamic parameters we were the $\mathrm{PiCCO} \circledast$ thermodilution system (PiCCO ${ }^{\circledR}$ catheter, Pulsion Medical Systems, Munich, Germany). Finally, the incision was closed with 2/0 vycril and finally the animal's skin with $2 / 0$ silk. During the surgery, to check the activity of the enzyme, a $0.5 \mathrm{~cm}$ incision was made in the abdomen through which an endoscopic camera was inserted to control the viability of the procedure and adjust the washing times. All animals received adequate analgesia (tramadol $5 \mathrm{mg} / \mathrm{Kg}$, post-surgery) for 24 hours.

24 after treatment, the animals were operated under inhalational anesthesia by abdominal midline incision. Once abdomen examined and the sample collection procedure is finished, animals were 
euthanized with sodium thiopental intravenously.

In order to minimize possible confounding factors, all studies were carried out by the same team, only a researcher knew the applied treatment and the coding of the samples generated.

\section{Samples to collection.}

During surgery, physiological parameters were recorded (heart rate, $\mathrm{PO}_{2}$, temperature, etc). Pre and posttreatment peritoneal lavage, samples were collected to analyze collagenase levels.

In all cases blood samples were collected in 4 steps of procedure: after anesthetic induction, prior to surgery, immediately after the completion of the peritoneal lavage, immediately after collagenase treatments(groups 2 and 3), and at $24 \mathrm{~h}$ after peritoneal lavage. The following blood parameters were tested: ions, liver and pancreatic enzymes, blood count, and clotting. An external laboratory performed enzyme-linked immunosorbent assay (ELISA) tests against Matrix Metalloproteinase-1 (MMP1) and 2 (MMP2) according to the manufacturer's recommendations (Invitrogen). For the statistical significance in MMP1 and MMP2 values, the Student's t test was used, calculated by Microsoft's Excel software on the absorbance values distributed in 3 groups.

Animals were necropsies $24 \mathrm{~h}$ after treatment, and the organs and tissues were analyzed at a macroscopic level analyzing damaged tissues, bleeding and adhesions.

\section{Histological Studies}

We also made histological examination of the samples of abdominal organs (spleen, liver, small intestine and kidney) and of the serose membranes related (peritoneum and pleura). We also analyzed large intestine and abdominal wall in order to observed same alteration by collagenase lavage.

After fixing the different samples in $4 \%$ formalin at room temperature, these were transferred with a numerical coded to the Department of Human Histology in Rey Juan Carlos University (Madrid, Spain) for analysis.The fixed tissues were embedded in paraffin and cut into 5-micron-thick slices. Sections were stained with hematoxylin-eosin. All were studied under a Zeiss Axiophot 2 microscope and photographed with an AxiocamHRc camera.

\section{Results}

No complications were observed during and post-surgeries. 4h after surgery all animals drank water, normal mobility and showed no signs of pain. The images during the treatments showed the release of peritoneal stroma during the washes in the collagenase groups. No macroscopic changes were observed pretreatments and $24 \mathrm{~h}$ after them. There was no adhesion formation or bleeding in any case.

No analytical, biochemical and hematological values in blood outside the usual parameters were observed in any case, group or time (pre, post and $24 \mathrm{~h}$ ). Only fibrinogen value was higher $24 \mathrm{~h}$ after 
treatment in all groups.

For collagenase levels in peritoneal lavage (post-lavage) and blood (pre-treatment, post-treatment and $24 \mathrm{~h}$ post-treatment), all samples were sent coded to Living Cells company (Fuenlabrada, Spain).

The results of quantification of MMP1 and MMP2 measured by absorbance did not show differences in collagenase levels in blood or peritoneal lavage. In the MMP1 measurements, 2 samples had slightly elevated levels of collagenase in the blood, values from 0.019 to 0.056 and 0.62 respectively and correspond to 1 pre-treatment and 1 post-treatment samplesin 2 different animals of group 2 (Table 1).Regarding the MMP2 data, all the values were similar and high values, implying that they were not assessable data, except for the absence of statistically significant differences between samples. (Table 1). 
Table 1

ELISA tests against Matrix Metalloproteinase- 1 and 2 in blood.

\begin{tabular}{|c|c|c|c|c|c|c|}
\hline \multirow{2}{*}{$\begin{array}{l}\text { Samples } \\
\text { code }\end{array}$} & \multicolumn{3}{|l|}{ MMP1 } & \multicolumn{3}{|l|}{ MMP2 } \\
\hline & Sample & A $450 / 595 \mathrm{~nm}$ & $\mathrm{ng} / \mathrm{mL}$ & Sample & A $450 / 595 \mathrm{~nm}$ & $\mathrm{ng} / \mathrm{mL}$ \\
\hline 2 & Pig 1 Pre & 0.0165 & 24.84 & Pig 1 Pre & 2.012 & 74.54 \\
\hline 5 & Pig 1 Post & 0.056 & 16.54 & Pig 1 Post & 1.448 & 47.62 \\
\hline 7 & Pig $124 h$ & 0.0155 & 25.44 & Pig $124 \mathrm{~h}$ & 2.052 & 76.33 \\
\hline 10 & Pig 2 pre & 0.014 & 25.29 & Pig 2 pre & 2.042 & 75.89 \\
\hline 14 & Pig 2 Post & 0.0225 & 14.62 & Pig 2 Post & 1.318 & 43.88 \\
\hline 18 & Pig 2 24h & 0.0195 & 26.57 & Pig 2 24h & 2.129 & 79.73 \\
\hline 20 & Pig 3 pre & 0.018 & 18.74 & Pig 3 pre & 1.5975 & 56.23 \\
\hline 17 & Pig 3 post & 0.02 & 23.28 & Pig 3 post & 1.905 & 69.84 \\
\hline 9 & Pig $324 \mathrm{~h}$ & 0.018 & 32.79 & Pig 3 24h & 2.551 & 98.38 \\
\hline 6 & Pig 4 pre & 0.0195 & 18.19 & Pig 4 pre & 1.560 & 54.59 \\
\hline 3 & Pig 4 post & 0.018 & 31.02 & Pig 4 post & 2.431 & 93.08 \\
\hline 11 & Pig 4 24h & 0.062 & 26.07 & Pig 4 24h & 2.095 & 78.23 \\
\hline 13 & Pig 5 pre & 0.0385 & 20.86 & Pig 5 pre & 1.741 & 62.59 \\
\hline 19 & Pig 5 post & 0.0165 & 17.20 & Pig 5 post & 1.905 & 69.84 \\
\hline 21 & Pig 5 24h & 0.021 & 25.46 & Pig 5 24h & 2.054 & 76.40 \\
\hline 16 & Pig 6 pre & 0.033 & 14.93 & Pig 6 pre & 1.338 & 44.79 \\
\hline 15 & Pig 6 post & 0.018 & 14.79 & Pig 6 post & 1.329 & 44.37 \\
\hline 12 & Pig 6 24h & 0.018 & 29.39 & Pig 6 24h & 2.320 & 88.17 \\
\hline 8 & Pig 7 pre & 0.0195 & 28.22 & Pig 7 pre & 2.241 & 84.66 \\
\hline 4 & Pig 7 post & 0.0095 & 26.54 & Pig 7 post & 2.127 & 79.62 \\
\hline 1 & Pig $724 h$ & 0.0165 & 24.32 & Pig $724 h$ & 1.976 & 72.97 \\
\hline 24 & Pig 8 pre & 0.0155 & 25.44 & Pig 8 pre & 1.905 & 69.84 \\
\hline 22 & Pig 8 post & 0.0146 & 25.32 & Pig 8 post & 2.040 & 75.88 \\
\hline $\begin{array}{l}\text { LEGEND T } \\
\text { data is the } \\
\text { absorban } \\
\text { collagena } \\
\text { sample } 8\end{array}$ & $\begin{array}{l}\text { e 1. Absork } \\
\text { ean of the } \\
\text { eeasures is } \\
\text { Pig sampl } \\
\text { esponds tc }\end{array}$ & $\begin{array}{l}\text { values at } 45 \\
\text { cates. The ext } \\
\text { uded. Sample } \\
7 \text { correspond } \\
\text { up } 3 \text { (control g }\end{array}$ & $\begin{array}{l}\text { n, taking } \\
\text { olated co } \\
\text { m Pig } 1 \\
\text { eatment } \\
\text { p). }\end{array}$ & $\begin{array}{l}595 \mathrm{~nm} \text { rea } \\
\text { entration of } \\
\text { orrespond } t \\
\text { up } 2 \text { (1000 }\end{array}$ & $\begin{array}{l}\text { as the noise va } \\
\text { MMP1 and MM } \\
\text { eatment group } 1 \\
\text { DU collagenase) }\end{array}$ & $\begin{array}{l}\text { The } \\
000 \mathrm{CDU} \\
\text { dd }\end{array}$ \\
\hline
\end{tabular}




\begin{tabular}{|c|c|c|c|c|c|c|}
\hline \multirow{2}{*}{$\begin{array}{l}\text { Samples } \\
\text { code }\end{array}$} & \multicolumn{3}{|l|}{ MMP1 } & \multicolumn{3}{|l|}{ MMP2 } \\
\hline & Sample & A $450 / 595 \mathrm{~nm}$ & $\mathrm{ng} / \mathrm{mL}$ & Sample & A $450 / 595 \mathrm{~nm}$ & $\mathrm{ng} / \mathrm{mL}$ \\
\hline 23 & Pig $824 h$ & 0.0145 & 25.32 & Pig 8 24h & 1.561 & 54.59 \\
\hline \multicolumn{7}{|c|}{$\begin{array}{l}\text { LEGEND Table } 1 \text {. Absorbance values at } 450 \mathrm{~nm} \text {, taking the } 595 \mathrm{~nm} \text { reading as the noise value. The } \\
\text { data is the mean of the duplicates. The extrapolated concentration of the MMP1 and MMP2 } \\
\text { absorbance measures is included. Samples from Pig } 1-5 \text { correspond to treatment group } 1 \text { (50000CDU } \\
\text { collagenase); Pig samples } 6-7 \text { correspond to treatment group } 2 \text { (100000CDU collagenase); and } \\
\text { sample } 8 \text { corresponds to group } 3 \text { (control group). }\end{array}$} \\
\hline
\end{tabular}

The histologist's report states that altered structures were not observed in any abdominal organs studied of the animals of the different groups and concentrations of collagenase lavage with special interest in spleen, liver, small intestine and kidney by their connective tissue capsule (Figure 1).

We also studied the serous membranes, peritoneum and pleura. In none of them did we observe histological alterations that could be caused by collagen in any concentrations (Figure 2).

\section{Discussion}

Tumors characterized by an extracellular matrix with abundant collagen often have a poor response to drugs. The extracellular fibrous matrix of the tumor microenvironment acts as a barrier that hinders delivery of the large size molecules that compound the chemotherapy drugs to the cancer cells and therefore, decreases the tumor response[3]. These fibrous tumors include peritoneal cancers and metastases[10-11].In recent years, it has been shown that collagenase treatment is capable of limiting fibrosis in liver tumors[12]. But all these "in vitro" studies or on experimental models have to demonstrate, in addition to the efficacy of the treatment, safety before being transferred to clinical practice.

In our opinion, three aspects are essential to demonstrate safety: testing a large mammal, histophysiological control of the organs in contact with collagenase and the measurement of collagenase in blood to know any systemic effect. In our study, after controlling the collagenase concentration and the time of local application, we wanted to analyze these aspects on a porcine model.

An important point is the activity time of collagenase, in previous studies, same articles had demonstrated that at 30 minutes collagenase activity is residual using in peritoneal cavity of mice[5, 13]; in our assay and considering the high concentration of collagen existing in the peritoneal cavity, we are sure that in 30 minutes the catalytic activity of the enzyme has been "exhausted".

Our results have shown that there is no post-treatment suffering in the animals despite using two doses of collagenase that are capable of releasing peritoneal stromal material.We have not observed alterations in the biochemical or hematological parameters in any of the 3 treatment groups, we only observed an elevation of the fibrinogen value at 4 and 24 hours after surgery constant in all groups, we consider that it can be associated with surgical process. 
The values of MMP1 and MMP2 in blood to detect systemic collagenase activity have been negative in all cases for MMP1, and the results of MMP2 have not shown differences between groups or time of collection of samples, although MMP2 is elevate in all cases, as the report received by the laboratory that has carried out the tests, indicates that there has been a cross-reaction of the antibody on other porcine metalloproteases.

Finally, macroscopic and histological study of the organs of the peritoneal cavity of all the animals has shown us that neither the peritoneal lavage with saline solution nor the treatments performed with collagenase alters the different organs at the proposed collagenase concentrations and in a lavage time of 30 minutes. Despite being observed in the peritoneal lavage residue tissue and stromal cells.

\section{Conclusions}

We had demostrated that lavage the peritoneal cavity for 30 minutes with 50000 or 100000 CDU of collagenase diluted in $1.5 \mathrm{~L}$ of saline solution between $36-38^{\circ} \mathrm{C}$ is safe and does not generate any sign of toxicity in the treated animals. This conclusion allows us, together with the efficacy data previously obtained in a rat model[5], to propose to the health authorities the use of collagenase lavage of the peritoneal cavity in a clinical trial for the conditioning or treatment of solid peritoneal tumors.

\section{Abbreviations}

ARRIVE guidelines

Animals in Research:reporting In Vivo Experiments

CDU

Collagen Digestion Unit.

ELISA

Enzyme-Linked ImmunoSorbent Assay.

HIPEC

Hyperthemic IntraPeritoneal Chemotheraty

MMP 1

Matrix Metalloproteinase I

MMP 2

Matrix Metalloproteinase II

OEBA

Ethical Committee on Animal Welfare

\section{Declarations}

Acknowledgment 
The authors acknowledge to the staff of the animal facility for their collaboration and especially Dr. C. Castilla for the anesthesia of the animals. Also to Combat Medical company for the transfer of the peritoneal lavage system and especially Mr. Mariano Coronado for his support during the surgeries. We thank Oliver Shaw (Instituto de Investigación Sanitaria-Fundación Jiménez Díaz) for revising the manuscript for aspects related to the English language

\section{Author Contributions}

M. G-A contributions to the conception and design of the work, drafting the manuscript, data analysis and interpretation, critical review of content, final approval of the version to be published. P.V-C: contributions to the design of the work, performing the experiments, critical review of content, final approval of the version to be published. J. B: data collection, performing the experiments, final approval of the version to be published. S. G. G-H: performing the histological experiments, design of figures, final approval of the version to be published. L. V-C: performing the experiments, data analysis and interpretation, final approval of the version to be published. H. G: performing the experiments, critical revision of the paper, final approval of the version to be published. D. G-O: contributions to the conception and design of the work, performing the experiments, critical review of content, final approval of the version to be published.

\section{Declarations of interest.}

Ethics approval and consent to participate: The present study was approved by the Research Ethics Committee of the University Hospital Fundación Jiménez Díaz and Community of Madrid (No.PROEX93.1/20) All experiments were performed following national and international regulations on the protection of experimental animals.

\section{License agreement}

1. I am authorized by my co-authors to enter into these arrangements.

2. I warrant, on behalf of myself and my co-authors, that:

o the article is original, has not been formally published in any other peer-reviewed journal, is not under consideration by any other journal and does not infringe any existing copyright or any other third party rights;

- I am/we are the sole author(s) of the article and have full authority to enter into this agreement and in granting rights to BMC are not in breach of any other obligation;

- the article contains nothing that is unlawful, libellous, or which would, if published, constitute a breach of contract or of confidence or of commitment given to secrecy;

- I/we have taken due care to ensure the integrity of the article. To my/our - and currently accepted scientific - knowledge all statements contained in it purporting to be facts are true and any formula or 
instruction contained in the article will not, if followed accurately, cause any injury, illness or damage to the user.

3. I, and all co-authors, agree that the article, if editorially accepted for publication, shall be licensed under the Creative Commons Attribution License 4.0. In line with BMC's Open Data Policy, data included in the article shall be made available under the Creative Commons 1.0 Public Domain Dedication waiver, unless otherwise stated. If the law requires that the article be published in the public domain, l/we will notify BMC at the time of submission, and in such cases not only the data but also the article shall be released under the Creative Commons 1.0 Public Domain Dedication waiver. For the avoidance of doubt it is stated that sections 1 and 2 of this license agreement shall apply and prevail regardless of whether the article is published under Creative Commons Attribution License 4.0 or the Creative Commons 1.0 Public Domain Dedication waiver.

Singed: Dr. Mariano García-Arranz

\section{Availability of data and material.}

The datasets analysed during the current study available from the corresponding author on reasonable request

\section{Competing interests.}

Authors D. G-O, M.G-A, H.G, J. B and L V-C have applied for 1 patent related titled "Chemical Scalpel" (EP 19382118.8).

Authors P. V-C and S. G. G-H declare no competing interests.

\section{Funding.}

This study has been funded by grant Instituto de Salud Carlos III (ISCIII) and co-founded by FEDER (PI19/01263).

\section{References}

1. Werb Z, Lu P. The Role of Stroma in Tumor Development. Cancer J. 2015;21:250-3. DOI:10.1097/PPO.0000000000000127.

2. Dolor A, Szoka FC. Digesting a Path Forward: The Utility of Collagenase Tumor Treatment for Improved Drug Delivery. Mol. Pharm.2018;15:2069-2083. DOI:

10.1021/acs.molpharmaceut.8b00319. 
3. Henke E, Nandigama R, Ergün S. Extracellular Matrix in the Tumor Microenvironment and Its Impact on Cancer Therapy. Frontiers in Molecular Biosciences. 2020;6:160. DOI:10.3389/fmolb.2019.00160.

4. Xu F, Huang X, Wang Y, Zhou SA, Size-Changeable. Collagenase-Modified Nanoscavenger for Increasing Penetration and Retention of Nanomedicine in Deep Tumor Tissue. Adv Mater. 2020;32(16):e1906745. DOl:10.1002/adma.201906745.

5. García-Olmo D, Villarejo Campos P, Barambio J, Gomez-Heras SG, Vega-Clemente L, OlmedillasLopez S, et al. Intraperitoneal collagenase as a novel therapeutic approach in an experimental model of colorectal peritoneal carcinomatosis. Sci Rep. 2021;11(1):503. DOI:10.1038/s41598-020-79721-0.

6. Zinger A, Koren L, Adir O, Poley M, Alyan M, Yaari Z, et al. Collagenase Nanoparticles Enhance the Penetration of Drugs into Pancreatic Tumors. ACS Nano. 2019;22(10):11008-21. DOI:10.1021/acsnano.9b02395. 13 ) .

7. Choi J, Credit K, Henderson K, Deverkadra R, He Z, Wiig H, et al. Intraperitoneal immunotherapy for metastatic ovarian carcinoma: Resistance of intratumoral collagen to antibody penetration. Clin Cancer Res. 2006;15(6):1906-12. DOI:10.1158/1078-0432.CCR-05-2141. 12 ) .

8. Bowie EJ, Owen CA Jr, Zollman PE, Thompson JH Jr, Fass DN. Tests of hemostasis in swine: normal values and values in pigs affected with von Willebrand's disease. Am J Vet Res. 1973;34(11):14057.

9. Kilkenny C, Browne WJ, Cuthill IC, Emerson M, Altman DG. Improving Bioscience Research Reporting: The ARRIVE Guidelines for Reporting Animal Research. PLoS Biol. 2010;8(6):e1000412. DOI:10.1371/journal.pbio.1000412.

10. Cadamuro M, Stecca T, Brivio S, Mariotti V, Fiorotto R, Spirli C, et al. The deleterious interplay between tumor epithelia and stroma in cholangiocarcinoma. Biochim Biophys Acta Mol Basis Dis. 2018;1864(4):1435-43. DOl:10.1016/j.bbadis.2017.07.028.

11. Natarajan S, Foreman KM, Soriano MI, Rossen NS, Shehade H, Fregoso DR,. et al. Collagen remodeling in the hypoxic tumor- mesothelial niche promotes ovarian cancer metastasis. Cancer Res. 2019;79:2271-84. DOI:10.1158/0008-5472.CAN-18-2616.

12. Baglieri J, Zhang C, Liang S, Liu X, Nishio T, Rosenthal SB, et al. Non-degradable collagen increases liver fibrosis but not hepatocellular carcinoma in mice. Am J Pathol. 2021;10:S0002-9440(21)002546. DOI: 10.1016/j.ajpath.2021.05.019.

13. Xu F, Huang X, Wang Y, Zhou SA, Size-Changeable. Collagenase-Modified Nanoscavenger for Increasing Penetration and Retention of Nanomedicine in Deep Tumor Tissue. Adv Mater. 2020;32(16):e1906745. DOI:10.1002/adma.201906745.

\section{Figures}



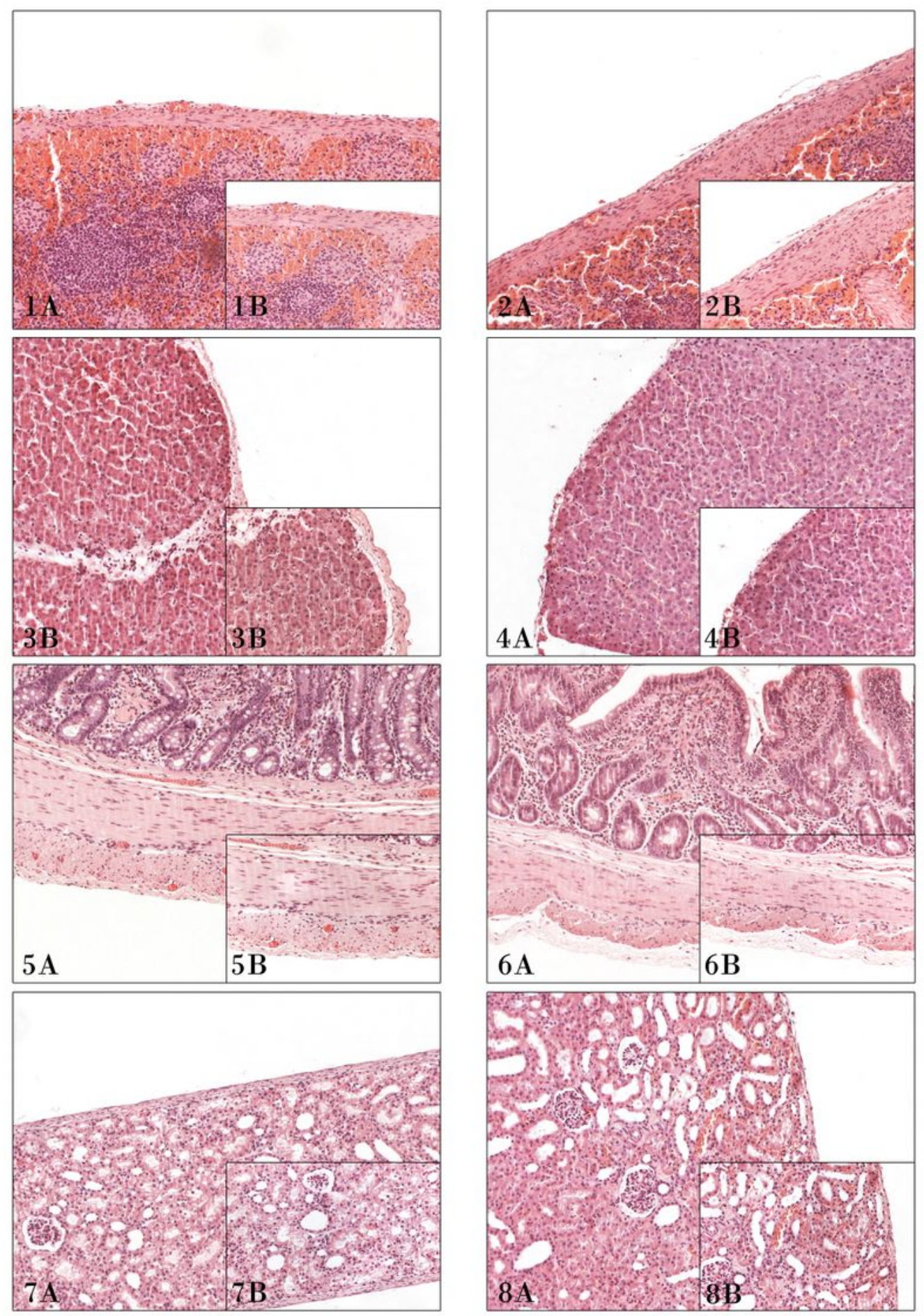

\section{Figure 1}

Histological study of principal peritoneal organs in treated groups Histological images of the abdominal organs studied. Spleen (image 1), liver (image 3), small intestine (image 5) and kidney (image 7)of the group of animals treated with $50.000 \mathrm{CDU}$ of collagenase. Spleen (image 2), liver (image 4), small intestine (image 6) and kidney (image 8) of the group of animals treated with $100.000 \mathrm{CDU}$ of collagenase. Hematoxylin-eosin. Figures A: 100x. Figures B: 200x. 

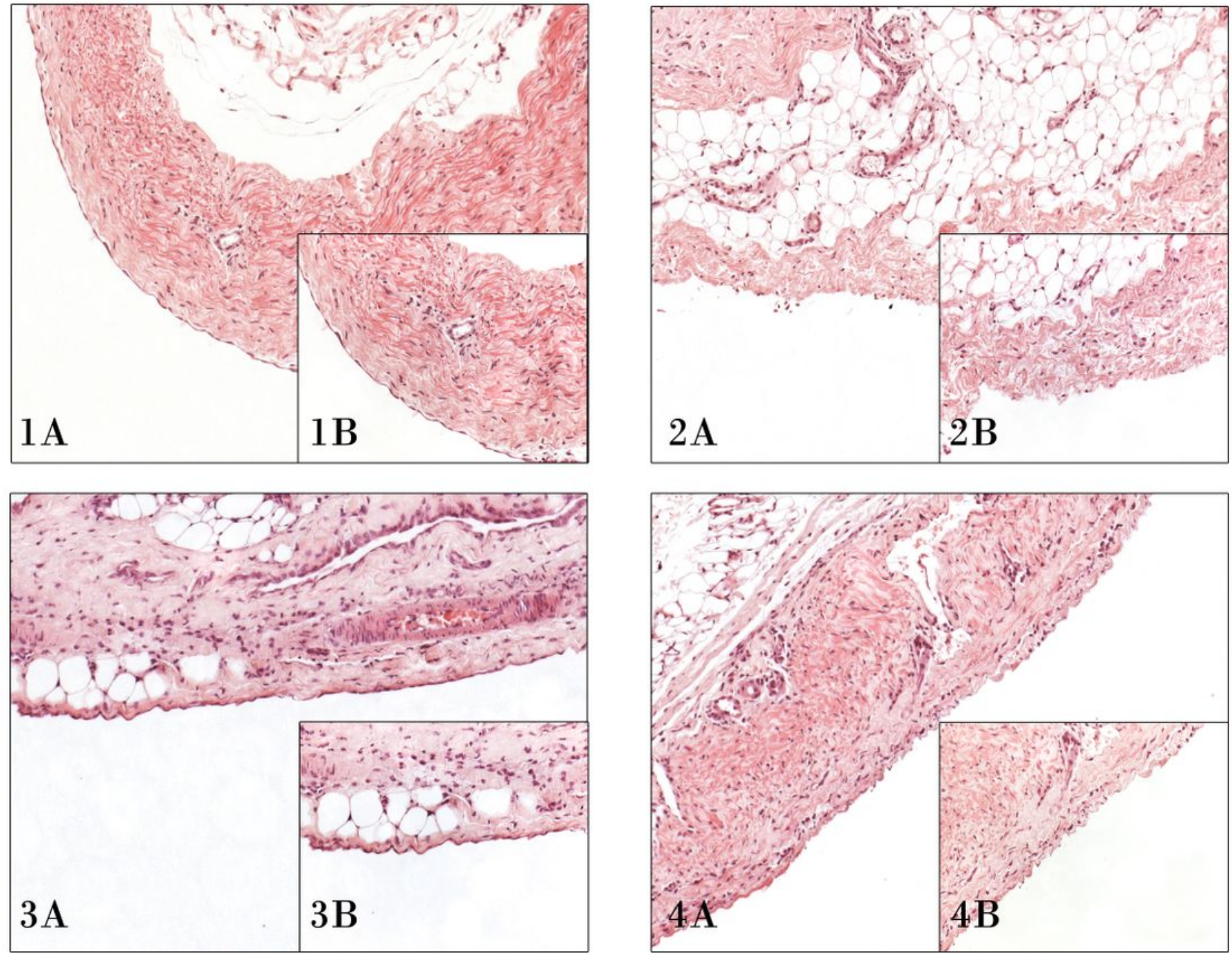

Figure 2

Histological study of serous membranes in treated groups Histological images of the serous membranes studied. Peritoneum (image 1) and pleura (image 3) in group of animals treated with $50.000 \mathrm{CDU}$ of collagenase. Peritoneum (image 2) and pleura (image 4)of group of animals treated with $100.000 \mathrm{CDU}$ of collagenase. Hematoxylin-eosin. Figures A: 100x. Figures B: 200x. 